\title{
Effect of the Position of Reaction-Site in Amphipathic-Type Thioester in Aqueous Amidation Reaction
}

\author{
Ikumi Otomo, Chiaki Kuroda* \\ Department of Chemistry, Rikkyo University, Tokyo, Japan \\ Email: ${ }^{*}$ chkkuroda@rikkyo.ac.jp
}

Received 21 April 2015; accepted 27 June 2015; published 30 June 2015

Copyright (C) 2015 by authors and Scientific Research Publishing Inc.

This work is licensed under the Creative Commons Attribution International License (CC BY). http://creativecommons.org/licenses/by/4.0/

(c) (i) Open Access

\begin{abstract}
Amphipathic-type thioesters $\mathrm{CH}_{3}\left(\mathrm{CH}_{2}\right)_{\mathrm{m}} \mathrm{COS}\left(\mathrm{CH}_{2}\right)_{n} \mathrm{COONa}(\mathrm{m}+\mathrm{n}=12)$ were synthesized and their reaction with various alkylamines was examined. Compounds having thioester moiety close to carboxylate $(m=10, n=2)$ afforded the corresponding amides in good yields, while the substrate having thioester moiety distant from carboxylate $(m=2, n=10)$ afforded the amides in relatively low yield. In all cases, the difference in yield due to the chain length of amine was not observed. The results indicated that the reaction took place effectively near the surface of micelle. However, the reaction was found to occur not only on micelle surface but also in solution.
\end{abstract}

\section{Keywords}

Hydrophobic Effect, Amides, Thioesters

\section{Introduction}

Organic reactions in aqueous media are useful in organic chemistry because of not only convenience and harmlessness but also unique chemical behavior [1], in which hydrophobic interaction between substrates is thought to be an important factor [2]. We are studying on the formation of amides from thioesters and amines in water, which is one of fundamental reactions in biochemistry. Previously, Kawabata and Kinoshita reported that dimerization reaction of thioalanine or thiophenylalanine $S$-dodecyl ester in water proceeded in higher yield than the corresponding $S$-ethyl ester, in the presence of pyridine [3], and the reaction was explained by a formation of micelle [4]. Polyamino acids was also synthesized by the related method [5]. We reported the presence of hydrophobic effect in the amidation reaction of $S$-dodecyl heptanethioate (1) or dodecanethioate (2) with $n$-alky-

*Corresponding author.

How to cite this paper: Otomo, I. and Kuroda, C. (2015) Effect of the Position of Reaction-Site in Amphipathic-Type Thioester in Aqueous Amidation Reaction. Advances in Chemical Engineering and Science, 5, 311-316.

http://dx.doi.org/10.4236/aces.2015.53032 
lamine $\mathbf{3}$ in water [6]. The reaction was considered to proceed in micelle and the yield of the products $\mathbf{4}$ or $\mathbf{5}$ depended primarily on the chain-length of amine 3 (Scheme 1). Namely, long-chain alkylamine, such as dodecylamine, afforded the corresponding amide in good yield, while no amide was obtained from amine having shorter alkyl chain. We also reported the reaction of amphipathic thioesters 6 or 7 with $n$-alkylamines 3 [7]. In the reaction, the yield of the corresponding amides primarily depended on the chain-length of the thioesters (i.e., 6 or 7) but not on that of $n$-alkylamine.

Kawabata and Kinoshita reported that their amidation reaction occurred at the surface of micelle [3] [4]. Similarly, the reaction of $\mathbf{1}$ or $\mathbf{2}$ was considered to proceed at the micelle surface [6]. In contrast, the micelle surface of each $\mathbf{6}$ and $\mathbf{7}$ is occupied by carboxylate moiety which is not a reactive function. The reactive function, i.e., the thioester moiety, may be located slightly inside of micelle, suggesting that the reactivity of the amphipathic-type thioesters depends on the position of the reaction site in hydrophobic chain. Then, we prepare amphipathic-type thioesters having various chain-length between the two functionalities, carboxylate and thioester, and here report that the reactivity depends on the position of the reaction site in hydrophobic chain.

\section{Results and Discussion}

In the present study, compounds $\mathbf{7}$ - $\mathbf{1 1}$ were used as the substrates. These compounds have the same total chain length $(m+n=12)$ with different length between two functionalities. Namely, the thioester moiety in $7(m=10$, $\mathrm{n}=2$ ) locates near the micelle surface while that of $\mathbf{1 1}(\mathrm{m}=2, \mathrm{n}=10)$ inside. These compounds were prepared according to the previous method [7] [8].

$$
\prod_{O} Y_{n} \mathrm{COO}^{\ominus} \mathrm{Na}^{\oplus} \quad \begin{aligned}
& 7 \mathrm{~m}=10, \mathrm{n}=2 \\
& 8 \mathrm{~m}=8, \mathrm{n}=4 \\
& 9 \mathrm{~m}=6, \mathrm{n}=6 \\
& 10 \mathrm{~m}=4, \mathrm{n}=8 \\
& 11 \mathrm{~m}=2, \mathrm{n}=10
\end{aligned}
$$

Compounds 7 - 11 were reacted with various $n$-alkylamines 3a-e, and the results are listed in Scheme 2 and Table 1. All reactions were carried out under the same conditions described previously (r.t., 24 h, about $13 \mathrm{mM}$ which is more than CMC of 7 - 11) [7]. The reaction of 7 (entries 1 - 5) was re-investigation of the previous study [7], however, the yield of 12a was much improved when EtOAc was used as the extracting solvent (entry 1). Then, EtOAc was used in all the other reactions. Compounds 7 and $\mathbf{8}$ afforded amides 12a-e and 13a-e, respectively, in good yields (entries 1 - 10). Thioesters $\mathbf{9}$ and $\mathbf{1 0}$ afforded the corresponding amides 14a-e and 15a-e, respectively, in relatively lower yields (entries 11 - 20), while compound 11 afforded 16a-e in distinctly low yields (entries 21 - 25). In any thioesters, the difference in yield due to the chain length of amine was not observed, suggesting that the primary factor to determine the yield was the structure of amphipathic thioesters 7 $\mathbf{1 1}$ but not amine 3a-e, as observed previously [7].

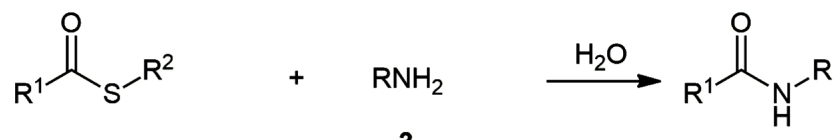

$$
\begin{aligned}
& 1 \mathrm{R}^{1}=n-\mathrm{C}_{6} \mathrm{H}_{13}, \mathrm{R}^{2}=n-\mathrm{C}_{12} \mathrm{H}_{25} \\
& 3 \\
& 2 \mathrm{R}^{1}=n-\mathrm{C}_{11} \mathrm{H}_{23}, \mathrm{R}^{2}=n-\mathrm{C}_{12} \mathrm{H}_{25} \\
& 6 \mathrm{R}^{1}=n-\mathrm{C}_{6} \mathrm{H}_{13}, \mathrm{R}^{2}=\left(\mathrm{CH}_{2}\right)_{2} \mathrm{COONa} \\
& 7 \mathrm{R}^{1}=n-\mathrm{C}_{11} \mathrm{H}_{23}, \mathrm{R}^{2}=\left(\mathrm{CH}_{2}\right)_{2} \mathrm{COONa} \\
& 5 \mathrm{R}^{1}=n-\mathrm{C}_{11} \mathrm{H}_{23}
\end{aligned}
$$

Scheme 1. See refs. [6] and [7] for the reaction conditions.

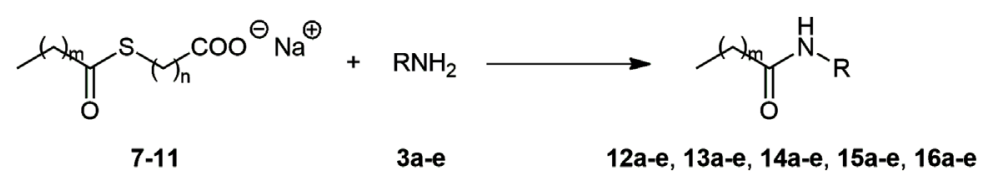

Scheme 2. Reaction conditions: r.t., 24 h, about $13 \mathrm{mM}$ in $\mathrm{H}_{2} \mathrm{O}$. See Table 1 for $\mathrm{m}, \mathrm{n}$, and $\mathrm{R}$. 
Table 1. Amidation reaction of thioesters $\mathbf{7}$ - $\mathbf{1 1}$ with amines 3a - e (r.t., 24 h) a

\begin{tabular}{|c|c|c|c|c|c|c|}
\hline Entry & Substrates & $\mathrm{m}$ & $\mathrm{n}$ & $\mathrm{R}$ & Product & Yield (\%) \\
\hline 1 & $7+3 a$ & 10 & 2 & $n-\mathrm{C}_{4} \mathrm{H}_{9}$ & $12 a$ & 85 (76) \\
\hline 2 & $7+3 b$ & 10 & 2 & $n-\mathrm{C}_{6} \mathrm{H}_{13}$ & 12b & $90(83)$ \\
\hline 3 & $7+3 c$ & 10 & 2 & $n-\mathrm{C}_{8} \mathrm{H}_{17}$ & $12 \mathrm{c}$ & 90 (77) \\
\hline 4 & $7+3 d$ & 10 & 2 & $n-\mathrm{C}_{10} \mathrm{H}_{21}$ & 12d & $85(82)$ \\
\hline 5 & $7+3 e$ & 10 & 2 & $n-\mathrm{C}_{12} \mathrm{H}_{25}$ & $12 e$ & $80(78)$ \\
\hline 6 & $\mathbf{8}+\mathbf{3 a}$ & 8 & 4 & $n-\mathrm{C}_{4} \mathrm{H}_{9}$ & $13 a$ & $91(80)$ \\
\hline 7 & $\mathbf{8}+3 \mathbf{b}$ & 8 & 4 & $n-\mathrm{C}_{6} \mathrm{H}_{13}$ & $13 b$ & 95 (89) \\
\hline 8 & $8+3 c$ & 8 & 4 & $n-\mathrm{C}_{8} \mathrm{H}_{17}$ & $13 c$ & $89(83)$ \\
\hline 9 & $8+3 d$ & 8 & 4 & $n-\mathrm{C}_{10} \mathrm{H}_{21}$ & 13d & $83(78)$ \\
\hline 10 & $8+3 e$ & 8 & 4 & $n-\mathrm{C}_{12} \mathrm{H}_{25}$ & $13 e$ & $91(74)$ \\
\hline 11 & $9+3 a$ & 6 & 6 & $n-\mathrm{C}_{4} \mathrm{H}_{9}$ & $14 a$ & $70(65)$ \\
\hline 12 & $9+3 b$ & 6 & 6 & $n-\mathrm{C}_{6} \mathrm{H}_{13}$ & $14 b$ & $79(60)$ \\
\hline 13 & $9+3 c$ & 6 & 6 & $n-\mathrm{C}_{8} \mathrm{H}_{17}$ & $14 \mathrm{c}$ & 75 (57) \\
\hline 14 & $9+3 d$ & 6 & 6 & $n-\mathrm{C}_{10} \mathrm{H}_{21}$ & 14d & $80(49)$ \\
\hline 15 & $9+3 e$ & 6 & 6 & $n-\mathrm{C}_{12} \mathrm{H}_{25}$ & $14 \mathrm{e}$ & $72(63)$ \\
\hline 16 & $10+3 a$ & 4 & 8 & $n-\mathrm{C}_{4} \mathrm{H}_{9}$ & $15 a$ & $77(51)$ \\
\hline 17 & $10+3 b$ & 4 & 8 & $n-\mathrm{C}_{6} \mathrm{H}_{13}$ & $15 b$ & $70(65)$ \\
\hline 18 & $10+3 c$ & 4 & 8 & $n-\mathrm{C}_{8} \mathrm{H}_{17}$ & $15 c$ & $79(71)$ \\
\hline 19 & $10+3 d$ & 4 & 8 & $n-\mathrm{C}_{10} \mathrm{H}_{21}$ & $15 d$ & 88 (59) \\
\hline 20 & $10+3 e$ & 4 & 8 & $n-\mathrm{C}_{12} \mathrm{H}_{25}$ & $15 e$ & 85 (69) \\
\hline 21 & $11+3 a$ & 2 & 10 & $n-\mathrm{C}_{4} \mathrm{H}_{9}$ & $16 a$ & $48(38)$ \\
\hline 22 & $11+3 b$ & 2 & 10 & $n-\mathrm{C}_{6} \mathrm{H}_{13}$ & $16 b$ & $56(47)$ \\
\hline 23 & $11+3 c$ & 2 & 10 & $n-\mathrm{C}_{8} \mathrm{H}_{17}$ & $16 \mathrm{c}$ & $58(32)^{c}$ \\
\hline 24 & $11+3 d$ & 2 & 10 & $n-\mathrm{C}_{10} \mathrm{H}_{21}$ & 16d & $54(36)$ \\
\hline 25 & $11+3 e$ & 2 & 10 & $n-\mathrm{C}_{12} \mathrm{H}_{25}$ & $16 e$ & $61(40)$ \\
\hline
\end{tabular}

a. Each substrate was mixed in distilled water and stirred at room temperature. Molar ratio of thioester/amine $=1 / 2$. b. Isolated yield after 24 h. Yield after $6 \mathrm{~h}$ reaction is shown in parenthesis. c. $65 \%$ yield after 7 days reaction.

To clarify the difference between substrates, the reaction was also carried out in a shorter reaction time (6 h) and the yields are shown in parenthesis (Table 1). A distinct difference in yield due to the thioester substrate was observed; namely, amides were isolated in ca. 80\% yield from 7, 8 (entries 1 - 10), 60\% from 9, 10 (eniries 11 - 20), and 40\% from 11 (eniries 21 - 25). Effect of long reaction time (7 days) was also examined using 11 and $3 \mathbf{c}$ as the substrates to obtain $\mathbf{1 6} \mathbf{c}$ in $65 \%$ yield, while no improvement in yield was observed in the reaction of $\mathbf{9}$ or $\mathbf{1 0}$ with 3c.

The results suggest that the amidation reaction takes place effectively near the surface of micelle. However, since $\mathbf{1 1}$ afforded the amides 16a-e, albeit lower yield, the reaction did not occur only on the micelle surface. Then, the reaction was carried out using shorter molecules $\mathbf{1 7}$ [8] and 3a under the same reaction conditions (13 $\mathrm{mM}$ in water) in which these compounds do not form micelle. As the result, the corresponding amide 16a was obtained in 36\% yield after $24 \mathrm{~h}$, and 32\% after $6 \mathrm{~h}$ (Scheme 3). As the reaction mixture was a clear solution, the result indicate that the reaction took place in solution. 


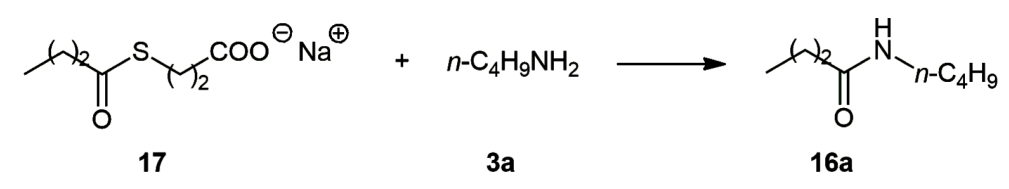

Scheme 3. Reaction conditions: r.t., 24 h, about $13 \mathrm{mM}$ in $\mathrm{H}_{2} \mathrm{O}$.

The mechanism of the observed effect can be explained as follows. Namely, the reaction occurs easily on micelle surface due to the presence of hydrophobic effect, as described previously [6], if the thioester group is positioned near the surface as in $\mathbf{7}$ (Figure 1, left). This effect is small in $\mathbf{1 1}$ because the two reaction sites, thioester and amino groups, are distant from each other in micelle. In solution, the reaction proceeds slowly because of lacking of hydrophobic effect (Figure 1, right).

\section{Conclusion}

Difference in yield of amides was observed in the reaction of amphipathic thioesters $\mathbf{7}$ - $\mathbf{1 1}$ with alkylamines $\mathbf{3 a}$ - e. The products were obtained in higher yields from the substrates having the thioester group close to the hydrophilic group, although the reaction was suggested to take place not only on micelle surface but also in bulk of the aqueous solution. The present results indicate that, in addition to hydrophobic effect, position of the functionality is an important factor in aqueous organic reactions.

\section{Experimental}

\subsection{General}

Melting points were measured on a Laboratory Devices Mel-Temp apparatus. IR spectra were recorded on a Jasco FT/IR-230 spectrometer. Both ${ }^{1} \mathrm{H}$ and ${ }^{13} \mathrm{C}$ NMR spectra were measured on a Jeol ECX-400P $(400 \mathrm{MHz}$ for ${ }^{1} \mathrm{H}$; $100 \mathrm{MHz}$ for ${ }^{13} \mathrm{C}$ ) spectrometer in $\mathrm{CDCl}_{3}$ as the solvent. Chemical shifts were recorded on the $\delta$ scale (ppm) with tetramethylsilane as an internal standard. For ${ }^{13} \mathrm{C} \mathrm{NMR}$, the signal of the solvent $\left(\mathrm{CDCl}_{3}=77.0 \mathrm{ppm}\right)$ was used as the reference. Analytical TLC was done on precoated TLC plates (Kieselgel 60 F254, layer thickness $0.2 \mathrm{~mm}$ ). Wakogel C-200 was used for column chromatography.

\subsection{Synthesis of the Substrates}

The substrates were prepared from the corresponding acid chloride and thiol [9]. See previous report for the preparation of $\mathbf{1}$ [6], 2 [6], 6 [7], and 7 [7]. Compounds 8 - 11 were prepared by the same method. Compound 8 was obtained from decanoyl chloride and 5-mercaptopentanoic acid, the latter of which was prepared from commercial ethyl 5-bromopentanoate and thiourea according to the reported procedure [10]. Compound $\mathbf{9}$ was obtained from octanoyl chloride and 7-mercaptoheptanoic acid (prepared from ethyl 7-bromoheptanoate), compound $\mathbf{1 0}$ from hexanoyl chloride and 9-mercaptononanoic acid (prepared from 9-bromononanoic acid), and $\mathbf{1 1}$ from butanoyl chloride and 11-mercaptoundecanoic acid (prepared from 11-bromoundecanoic acid). Known compound $\mathbf{1 7}$ [8] was also prepared by the same method.

Compound 8: $\mathrm{Mp} 172.3^{\circ} \mathrm{C}-174.7^{\circ} \mathrm{C}$; IR (KBr) $1560,1441,1419 \mathrm{~cm}^{-1} ;{ }^{1} \mathrm{H}$ NMR as carboxylic acid $\delta 0.88$ (3H, t, $J=6.8 \mathrm{~Hz}), 1.24-1.33(12 \mathrm{H}, \mathrm{m}), 1.59-1.76(6 \mathrm{H}, \mathrm{m}), 2.38(2 \mathrm{H}, \mathrm{t}, J=7.2 \mathrm{~Hz}), 2.54(2 \mathrm{H}, \mathrm{t}, J=7.4 \mathrm{~Hz})$, $2.89(2 \mathrm{H}, \mathrm{t}, J=7.0 \mathrm{~Hz}) ;{ }^{13} \mathrm{C}$ NMR as carboxylic acid $\delta 14.1,22.7,23.7,25.7,28.2,28.9,29.0,29.2$ (2C), 29.4, 31.8, 33.1, 44.2, 177.4, 199.7 .

Compound 9: $\mathrm{Mp} 202.3^{\circ} \mathrm{C}-203.8^{\circ} \mathrm{C}$; IR (KBr) 1562, 1448, $1421 \mathrm{~cm}^{-1}$; ${ }^{1} \mathrm{H}$ NMR as carboxylic acid $\delta 0.88$ $(3 \mathrm{H}, \mathrm{t}, J=6.8 \mathrm{~Hz}), 1.24-1.70(18 \mathrm{H}, \mathrm{m}), 2.36(2 \mathrm{H}, \mathrm{t}, J=7.4 \mathrm{~Hz}), 2.53(2 \mathrm{H}, \mathrm{t}, J=7.5 \mathrm{~Hz}), 2.86(2 \mathrm{H}, \mathrm{t}, J=7.2$ $\mathrm{Hz}) ;{ }^{13} \mathrm{C}$ NMR as carboxylic acid $\delta 14.0,22.6,24.5,25.7,28.4,28.5,28.6,28.9$ (2C), 29.4, 31.6, 33.8, 44.2, 179.2, 199.9.

Compound 10: Mp $258.4^{\circ} \mathrm{C}$ (dec); IR (KBr) 1564, 1442, $1419 \mathrm{~cm}^{-1} ;{ }^{1} \mathrm{H}$ NMR as carboxylic acid $\delta 0.89$ (3H, t, $J=6.8 \mathrm{~Hz}), 1.24-1.40(12 \mathrm{H}, \mathrm{m}), 1.51-1.70(6 \mathrm{H}, \mathrm{m}), 2.35(2 \mathrm{H}, \mathrm{t}, J=7.5 \mathrm{~Hz}), 2.53(2 \mathrm{H}, \mathrm{t}, J=7.5 \mathrm{~Hz}), 2.86$ $(2 \mathrm{H}, \mathrm{t}, J=7.2 \mathrm{~Hz}) ;{ }^{13} \mathrm{C}$ NMR as carboxylic acid $\delta 13.8,22.3,24.6,25.4,28.7,28.7,28.9,28.9,29.0,29.5,31.1$, 34.0, 44.1, 179.6, 199.9 .

Compound 11: $\mathrm{Mp} 219.9^{\circ} \mathrm{C}-222.8^{\circ} \mathrm{C}$; IR $(\mathrm{KBr}) 1562,1446,1425 \mathrm{~cm}^{-1}$; ${ }^{1} \mathrm{H}$ NMR as carboxylic acid $\delta 0.95$ (3H, t, $J=7.3 \mathrm{~Hz}), 1.23-1.37(12 \mathrm{H}, \mathrm{m}), 1.51-1.74(6 \mathrm{H}, \mathrm{m}), 2.35(2 \mathrm{H}, \mathrm{t}, J=7.4 \mathrm{~Hz}), 2.52(2 \mathrm{H}, \mathrm{t}, J=7.4 \mathrm{~Hz})$, 


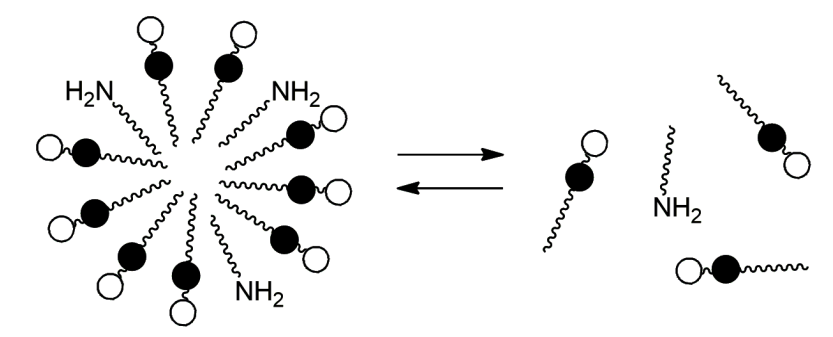

Figure 1. Micellar model of the reaction. White circle $=\mathrm{COO}^{-} \mathrm{Na}^{+}$,

black circle $=-\mathrm{C}(=\mathrm{O}) \mathrm{S}-$.

$2.86(2 \mathrm{H}, \mathrm{t}, J=7.2 \mathrm{~Hz}) ;{ }^{13} \mathrm{C}$ NMR as carboxylic acid $\delta 13.5,19.2,24.6,28.8$ (2C), 29.0, 29.0, 29.2, 29.3, 29.3, 29.5, 34.0, 46.0, 179.8, 199.8 .

\subsection{Typical Procedure of the Amidation Reaction}

Thioester 7 (0.065 mmol) was added to a stirred mixture of amine $3(0.13 \mathrm{mmol})$ in water $(5 \mathrm{ml})$, and the mixture was stirred at room temperature for $24 \mathrm{~h}$ (or $6 \mathrm{~h}$ ). The mixture was extracted with EtOAc, and the ethereal layer was washed with aqueous $\mathrm{NaHCO}_{3}$ solution, and dried over $\mathrm{Na}_{2} \mathrm{SO}_{4}$. After evaporation of the solvent, the product was purified by silica gel column chromatography using hexane/AcOEt as eluent to obtain the corresponding amides. The structures of the products were confirmed by comparison of the ${ }^{1} \mathrm{H}$ NMR spectra with those of reported [6] [11] [12].

\section{Acknowledgements}

Financial support was obtained from the Strategic Research Foundation Grant-aided Project for Private Universities from the Ministry of Education, Culture, Sports, Science, and Technology, Japan.

\section{References}

[1] (a) Lindström, U.M. (2007) Organic Reactions in Water. Blackwell Publishing, Oxford. http://dx.doi.org/10.1002/9780470988817

(b) Li, C.-J. (1993) Organic Reactions in Aqueous Media-With a Focus on Carbon-Carbon Bond Formation. Chemical Reviews, 93, 2023-2035. http://dx.doi.org/10.1021/cr00022a004

(c) Li, C.-J. and Chen, L. (2006) Organic Chemistry in Water. Chemical Society Reviews, 35, 68-82.

http://dx.doi.org/10.1039/B507207G

(d) Lindström, U.M. (2002) Stereoselective Organic Reactions in Water. Chemical Reviews, 102, 2751-2772. http://dx.doi.org/10.1021/cr010122p

(e) Kobayashi, S. (2013) The New World of Organic Reactions in Water. Pure and Applied Chemistry, 85, 1089-1101. http://dx.doi.org/10.1351/PAC-CON-12-10-11

[2] (a) Breslow, R. (1991) Hydrophobic Effects on Simple Organic Reactions in Water. Accounts of Chemical Research, 24, 159-164. http://dx.doi.org/10.1021/ar00006a001

(b) Breslow, R., Groves, K. and Mayer, M.U. (1998) The Hydrophobic Effect as a Mechanistic Tool. Pure and Applied Chemistry, 70, 1933-1938. http://dx.doi.org/10.1351/pac199870101933

(c) Otto, S. and Engberts, J.B.F.N. (2003) Hydrophobic Interactions and Chemical Reactivity. Organic and Biomolecular Chemistry, 1, 2809-2820. http://dx.doi.org/10.1039/b305672d

[3] (a) Kawabata, Y. and Kinoshita, M. (1974) Studies on Functional Micelles, 1-Preparation of Cyclic Dipeptides from Phenylalanine S-Dodecyl Ester. Makromolekulare Chemie, 175, 105-110.

http://dx.doi.org/10.1002/macp.1974.021750112

(b) Kawabata, Y. and Kinoshita, M. (1975) Studies on Functional Micelles, 2-Micellar Effect on the Preparation of Cyclic Dipeptide from Thioalanine S-Dodecyl Ester. Makromolekulare Chemie, 176, 49-56. http://dx.doi.org/10.1002/macp.1975.021760105

[4] (a) Kawabata, Y. and Kinoshita, M. (1975) Studies on Functional Micelles, 4-Effect of Alkyl Chain Length on the Micellar Reaction of Thioalanine S-Alkyl Esters. Makromolekulare Chemie, 176, 2797-2805. http://dx.doi.org/10.1002/macp.1975.021761002

(b) Kawabata, Y. and Kinoshita, M. (1975) Studies on Functional Micelles, 5-Solvent and Salt Effects on the Micellar Condensation of Thioalanine S-Alkyl Esters. Makromolekulare Chemie, 176, 2807-2814. http://dx.doi.org/10.1002/macp.1975.021761003 
[5] Kunieda, N., Watanabe, M., Okamoto, K. and Kinoshita, M. (1981) Polycondensation of Thioglycine S-Dodecyl Ester Hydrobromide in Water. Makromolekulare Chemie, 182, 211-214. http://dx.doi.org/10.1002/macp.1981.021820122

[6] Torihata, A. and Kuroda, C. (2010) Hydrophobic Effect and Substrate Specificity in Reaction of Thioester and Amine in Water. Bulletin of the Chemical Society of Japan, 83, 1534-1538. http://dx.doi.org/10.1246/bcsj.20100143

[7] Torihata, A. and Kuroda, C. (2011) Reaction of Amphipathic-Type Thioester and Amine with Hydrophobic Effect in Water. Synlett, 2035-2038.

[8] Kurooka, S., Hashimoto, M., Tomita, M., Maki, A. and Yoshimura, Y. (1976) Relationship between the Structures of S-Acyl Thiol Compounds and Their Rates of Hydrolysis by Pancreatic Lipase and Hepatic Carboxylic Esterase. Journal of Biochemistry, 79, 533-541.

[9] Dellaria Jr., J.F., Nordeen, C. and Swett, L.R. (1986) The Facile and Efficient Preparation of Phenolic and Thiol Esters. Synthetic Communications, 16, 1043-1048. http://dx.doi.org/10.1080/00397918608056346

[10] (a) Lu, Y., Tanasova, M., Borhan, B. and Reid, G.E. (2008) Ionic Reagent for Controlling the Gas-Phase Fragmentation Reactions of Cross-Linked Peptides. Analytical Chemistry, 80, 9279-9287. http://dx.doi.org/10.1021/ac801625e

(b) Jessing, M., Brandt, M., Jensen, K.J., Christensen, J.B. and Boas, U. (2006) Thiophene Backbone Amide Linkers, a New Class of Easily Prepared and Highly Acid-Labile Linkers for Solid-Phase Synthesis. Journal of Organic Chemistry, 71, 6734-6741. http://dx.doi.org/10.1021/jo060687r

[11] Mathias, L.J. and Johnson, C.G. (1991) Solid-State NMR Investigation of Nylon 12. Macromolecules, 24, 6114-6122. http://dx.doi.org/10.1021/ma00023a011

[12] Tomioka, K., Sumiyoshi, T., Narui, S., Nagaoka, Y., Iida, A., Miwa, Y., Taga, T., Nakano, M. and Handa, T. (2001) Molecular Assembly and Gelating Behavior of Didodecanoylamides of $\alpha, \omega$-Alkylidenediamines. Journal of the American Chemical Society, 123, 11817-11818. http://dx.doi.org/10.1021/ja0169318 